\title{
REACTIONS IN NITROIMIDAZOLE AND
}

\section{METHYLNITROIMIDAZOLE TRIGGERED BY \\ LOW ENERGY (0 - 8 eV) ELECTRONS}

Katrin Tanzer, ${ }^{\neq}$Linda Feketeová, ${ }^{*, \$, \neq}$ Benjamin Puschnigg, ${ }^{*}$ Paul Scheier, ${ }^{*}$ Eugen Illenberger,${ }^{\S}$

Stephan Denifl ${ }^{*}, ¥$

${ }^{¥}$ Institut für Ionenphysik und Angewandte Physik and Center of Molecular Biosciences, Leopold Franzens Universität Innsbruck, Technikerstrasse 25, 6020 Innsbruck, Austria

${ }^{\$}$ Université de Lyon; Université Claude Bernard Lyon1; Institut de Physique Nucléaire de Lyon, CNRS/IN2P3 UMR 5822, 43 Bd du 11 novembre 1918, 69622 Villeurbanne Cedex, France

${ }^{\ddagger}$ ARC Centre of Excellence for Free Radical Chemistry and Biotechnology, School of Chemistry and Bio21 Institute of Molecular Science and Biotechnology, The University of Melbourne, 30 Flemington Road, Victoria 3010, Australia

${ }^{\S}$ Institut für Chemie und Biochemie-Physikalische und Theoretische Chemie, Freie Universität Berlin, Takustrasse 3, 14195 Berlin, Germany

KEYWORDS: radiosensitiser, nitroimidazole, low energy electrons, dissociative electron attachment 


\section{ABSTRACT}

Low energy electrons $(0-8 \mathrm{eV})$ effectively decompose 4-nitroimidazole (4NI) and the two methylated isomers 1-methyl-5-nitroimidazole and 1-methyl-4-nitroimidazole via dissociative electron attachment (DEA). The involved unimolecular decompositions range from simple bond cleavages (loss of $\mathrm{H}^{\circ}$, formation of $\mathrm{NO}_{2}{ }^{-}$) to complex reactions possibly leading to a complete degradation of the target molecule (formation of $\mathrm{CN}^{-}$, etc.). At energies below $2 \mathrm{eV}$ the entire rich chemistry induced by DEA is completely quenched by methylation as already demonstrated in a previous Communication (K. Tanzer, L. Feketeová, B. Puschnigg, P. Scheier, E. Illenberger, and S. Denifl, Angew. Chem. Int. E. 53 (2014) 12240). The observation that in 4NI neutral radicals and radical anions are formed via DEA at high efficiency already at threshold $(0 \mathrm{eV})$ may have significant implications for the development of nitroimidazole based radiosensitisers in tumour radiation therapy.

\section{INTRODUCTION}

Nitroimidazoles, based on model title compounds, are under investigation as radiosensitisers for hypoxic tumours ${ }^{1,2}$ which are solid tumours characterised by an invariably low-oxygen state compared to the normal tissue from which they emerged. An ideal radiosensitiser selectively binds to tumour cells and high energy irradiation (particles or photons in the $\mathrm{MeV}$ range) results in a selective death of the tumour cells with no or only little effect to the healthy tissue. The molecular mechanism, how radiosensitisers operate is not yet known and is the subject of intense research. It is, however, likely that reactions induced by low energy 
electrons (LEEs) involving dissociative electron attachment (DEA) play a significant role ${ }^{3}$. This notion is based on the fact, that the action of a high energy quantum with a living cell in the first step removes electrons from the molecular network of the cell. These (ballistic) secondary electrons are rapidly slowed down (on the ps $\left(10^{-12} \mathrm{~s}\right)$ time scale) thereby causing further excitation and ionisation events generating charged and neutral radicals and finally becoming bound on a fragment via DEA at low energies (below $2 \mathrm{eV}$ ). In many molecules, DEA is a very effective mean to break bonds and hence generate radicals at electron energies significantly below the corresponding bond dissociation energy. ${ }^{4,5}$ Bromouracil (BrU), e.g., is a well-known radiosensitiser which is formed from thymine ( $\mathrm{T}$ ) by replacing the methyl group by $\mathrm{Br}$. It has been shown in gas phase experiments that the DEA cross section in $\mathrm{BrU}$ (generating $\mathrm{Br}^{-}$and the corresponding radical) is by about two orders of magnitude larger than the DEA cross section in $\mathrm{T}$ (generating $\mathrm{H}$ and the corresponding dehydrogenated anion $(\mathrm{T}-\mathrm{H})-7 .{ }^{6,7} \mathrm{It}$ is likely, that in the course of radiotherapy treatment, radicals or ions which are very effectively generated (by low energy electrons) from the radiosensitiser will attack the tumour cells and hence low energy secondary electrons may significantly contribute to the action of the radiosensitiser.

For the characterisation of a radiosensitiser it is hence of particular significance to know its response towards low energy electrons. As will be shown in the present contribution, 4NI in fact effectively generates radicals at electron energies below $2 \mathrm{eV}$.

In a recent Communication ${ }^{8}$ we demonstrated that electron attachment to $4 \mathrm{NI}$ in the energy range $0-8 \mathrm{eV}$ leads to DEA reactions with ion yields characterised by a series of sharp resonances in the very low energy range (below $2 \mathrm{eV}$ ) followed by a broad and unstructured resonance in the energy range between $2 \mathrm{eV}$ and about $5 \mathrm{eV}$, with a peak maximum near 3.0 to $3.5 \mathrm{eV}$, its exact position dependent on the fragment ion under observation. Very surprisingly, in 
the corresponding methylated compound (4MeNI) DEA was completely blocked at energies below $2 \mathrm{eV}$, but still operative within the unstructured and broad resonance at higher energy. Methylation hence completely quenches DEA at low energies (below $2 \mathrm{eV}$ ) with its underlying rich chemistry. These sharp low energy resonances have been interpreted as vibrational Feshbach resonances (VFRs) which are electronic states of the transient anion in which the excess electron is weakly bound in the field of the vibrationally excited molecule. ${ }^{9} 4 \mathrm{NI}$ possesses a large dipole moment (in the range of $8 \mathrm{D}$ and hence much above the critical minimum value to bind an extra electron (about $2 \mathrm{eV}$ ), ${ }^{10}$ it is thus very likely that dipole bound states are involved. Dipole supported VFRs can in fact couple to valence configurations thereby acting as effective doorways for DEA. ${ }^{11}$

A study on electrospray ionisation on a series of nitroimidazoles ${ }^{12}$ showed that the parent radical anion $\left(\mathrm{M}^{\circ}\right)$ is often formed as the most abundant species while with this technique usually the deprotonated ion $(\mathrm{M}-\mathrm{H})^{-}$is the dominant one. It has been suggested that in cells which are deficient of oxygen, the formation of radical anions may play a significant role in action of the radiosensitiser. ${ }^{12}$

In our previous Communication, ${ }^{8}$ the quenching effect of methylation has been demonstrated in the case of two DEA reactions. Here we present the complete set of reactions operative in 4NI and its methylated forms Me4NI and Me5NI (see Figure 1 for molecular structures.) 


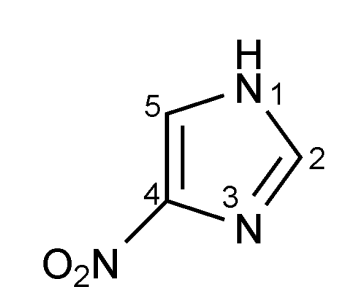

4-nitroimidazole (a)

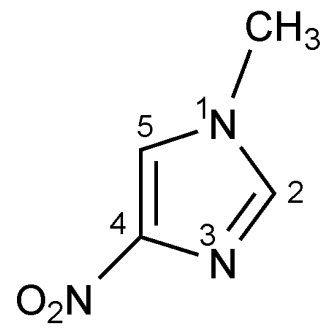

1-methyl-4-nitroimidazole (b)

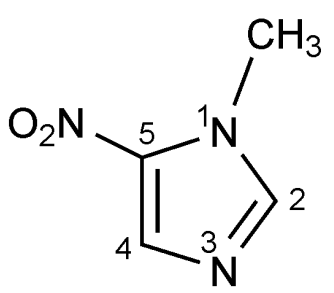

1-methyl-5-nitroimidazole (c)

Figure 1: molecular structures of (a) 4-nitroimidazole (4NI), (b) 1-methyl-4-nitroimidazole (Me4NI), and (c) 1-methyl-5-nitroimidazole (Me5NI).

\section{EXPERIMENTAL}

The experiments were performed by means of an electron spectrometer previously described in detail. ${ }^{13}$ It consists of a molecular beam system, a high resolution hemispherical electron monochromator (HEM) and a quadrupole mass filter with a pulse counting system for analysing and detecting the ions formed. In brief, the solid samples were evaporated in a resistively heated oven inside the vacuum chamber and then introduced via a capillary of $1 \mathrm{~mm}$ diameter into the interaction chamber of the HEM where they interact with the well-defined electron beam. The anions generated by the electron attachment process are extracted by a weak electrostatic field into the quadrupole mass filter where they are analysed and detected by the channeltron electron multiplier. After crossing the collision region, the remaining electrons are collected by a Faraday plate and the electron current is monitored during the experiments using a pico-ampèremeter. The HEM is able to deliver an electron beam at an energy distribution of about $35 \mathrm{meV}$ (full width at half maximum (FWHM)). In the course of the present experiments an energy resolution of $150 \mathrm{meV}$ (FWHM) at an electron current of $20 \mathrm{nA}$ was used which 
appeared to be a reasonable compromise between energy resolution and intensity. For determination of the energy spread and calibration of the energy scale the well known cross sections for the formation of $\mathrm{Cl}^{-}$(DEA) or $\mathrm{SF}_{6}{ }^{-}$(associative attachment) was used. ${ }^{14,15}$ The samples 4NI and Me5NI were purchased from Aldrich (stated purity $97 \%$ ) and Me4NI from BOC Sciences (stated purity $98 \%$ ) and used as delivered. It is observed that under comparable experimental conditions (evaporation temperature, pressure, electron intensity, etc.) the intensity of the ions arising from 4NI and Me5NI is on a comparable scale but that from Me4NI is by more than one order of magnitude lower. For 4NI, the evaporation temperature was $373 \mathrm{~K}$ and for both methylated compounds $333 \mathrm{~K}$.

\section{RESULTS AND DISCUSSION}

\section{General features and characterisation of the resonances}

Before describing the various DEA reactions in detail, we shall in this paragraph consider the general features of electron attachment to the title compounds and the nature of the resonances involved in the DEA reactions. From the relative cross sections (yields) presented in Figs. 2-8 it can be seen that a variety of negative fragment ions are formed from the three title compounds in the energy range between 0 and $8 \mathrm{eV}$. The three compounds show the following gross features:

1. Only the two methylated molecules do exhibit a mass spectrometrically observable parent radical anion (not shown here, formation of $\mathrm{Me} 4 \mathrm{NI}^{--}$is presented in the previous Communication, Ref. 8) 
2. DEA to 4NI and the two methylated counterparts generates identical fragment ions, however, with remarkably different ion yields in that the contribution below $2 \mathrm{eV}$ is completely quenched under methylation

3. The shapes of the ion yields arising from Me5NI closely resemble those arising from Me4NI.

As already mentioned above, the intensity of ions from Me4NI is significantly lower compared to Me5NI which implicates that some of the fragment ions observed from Me5NI were simply below the detection limit in the case of Me4NI.

The origin of this large difference is not yet clear. It is possible that the peculiarities of DEA can cause such a large difference. More precisely, the two isomers possess significantly different dipole moments (Me4NI: 4.37 D, Me5NI: $8.50 \mathrm{D}$ ) ${ }^{12}$ which may affect the lifetime of the transient anion and consequently the ion intensity.

In general DEA is a two step process, viz.,

$$
\begin{array}{r}
\mathrm{e}^{-}+\mathrm{M} \rightarrow \quad\left[\mathrm{M}^{{ }^{-}}\right]^{\#} \rightarrow \mathrm{R}^{\cdot}+\mathrm{X}^{-} \\
{\left[\mathrm{M}^{\cdot-}\right]^{\#} \rightarrow \mathrm{M}+\mathrm{e}^{-}}
\end{array}
$$

where in the first step a transitory anion $\left(\left[\mathrm{M}^{*}\right]^{\#}\right)$ is formed via a Franck-Condon transition. This transient negative ion (TNI) represents a quasi discrete quantum state (or scattering state) embedded in the continuum $\left(\mathrm{M}+\mathrm{e}^{-}\right)$which is hence unstable towards the loss of the extra electron (autodetachment). The decomposition into stable fragment ions ( $\mathrm{X}^{-}$, and further 
fragment ions) (1a) competes with autodetachment, recovering the neutral molecule (1b). The cross section for DEA (into $\mathrm{X}^{-}$) can be expressed as ${ }^{14,15}$

$\sigma_{\mathrm{DEA}}=\sigma_{0} \mathrm{P}\left(\mathrm{X}^{-}\right)$

where $\sigma_{0}$ is the electron attachment cross section generating the TNI and $\mathrm{P}\left(\mathrm{X}^{-}\right)$the probability for the TNI to decompose into fragment $\mathrm{X}^{-}$(with respect to the other DEA products and the probability to keep the extra electron (autodetachment) in the dissociating system until it becomes bound on the negatively charged fragment). $\mathrm{P}$ is a number between 0 and 1 , in the latter case autodetachment does not at all compete and only one single DEA reaction (into $\mathrm{X}^{-}$) is operative. While $\sigma_{0}$ is expected to have comparable values for both isomers, P may differ to some extend due to the different dipole moments, which may affect the coupling of the extra electron to the continuum and hence the autodetachment lifetime of the corresponding TNI. It has to be noted that many of the complex decomposition reactions present in the title compounds occur on time scales eventually extending to the $\mu$ s time regime and hence these reactions may strongly be affected by the autodetachment lifetimes leading to the different ion intensities from both isomers.

As shown in the previous Communication ${ }^{8}$ the non-decomposed parent anion in Me4NI is formed within a very narrow resonance right at threshold (close to $0 \mathrm{eV}$ ), and the same is observed in Me5NI (not shown here).

The common picture to rationalise the formation of metastable parent anions by capture of free electrons under collision free conditions is based on the notion that the electronic energy of the electron attaching system (comprised of the energy of the incoming electron and the electron affinity of the molecule) is effectively dispersed over the vibrational degrees of freedom 
in the temporary parent anion, thereby delaying autodetachment. ${ }^{14}$ A prototype system of resonant associative attachment is $\mathrm{SF}_{6}$, which possesses one of the highest electron attachment cross sections known and associated with a very narrow resonance near zero eV. ${ }^{15,16} \mathrm{In} \mathrm{SF}_{6}$, all DEA channels are endothermic and hence not accessible at zero $\mathrm{eV}$ (provided that the temperature of the target molecule is low), i.e., DEA does not compete with autodetachment. Together with the high symmetry of the molecule (6 equal S-F bonds) this provides favourable conditions for the formation of a metastable parent anion. It has to be noted that in the recently studied explosives trinitrotoluene (TNT) ${ }^{17}$ and dinitrobenzene (DNB) ${ }^{18}$ a competition between DEA and the formation of the non-decomposed parent anion has been observed. In all these cases formation of $\mathrm{M}^{-}$is restricted to a narrow energy range close to threshold. A remarkable example is electron attachment to $\mathrm{C}_{60}$ generating $\mathrm{C}_{60}{ }^{-}{ }^{-}$over a wide and structured feature extending from threshold $(0 \mathrm{eV})$ to about $12 \mathrm{eV} \cdot{ }^{19-21} \mathrm{C}_{60}$ is a comparatively large compound of high symmetry and equal binding energies for each $\mathrm{C}$ atom thereby providing ideal conditions for a delayed autodetachment resulting in a situation that $\mathrm{C}_{60}{ }^{-}{ }^{-}$can be observed on the mass spectrometric time scale at attachment energies up to $12 \mathrm{eV}$.

The title compounds are of low symmetry but in the methylated molecules, DEA is blocked at low energies. This apparently leads to conditions that electron capture at very low energies generates parent anions observable on a mass spectrometric scale. This is no longer the case for 4NI since (a) DEA via reaction (1) is already operative at threshold and such a decomposition usually takes place on time scales much below the $\mu$ s range and (b) the lower number of vibrational degrees of freedom (27 versus 36) provide a less effective means for energy redistribution making the observation of a metastable parent anion more unlikely. 
In 4NI no parent anion is observed, instead the molecule is subjected the loss of a neutral hydrogen atom according to the DEA reaction

$\mathrm{e}^{-}+\mathrm{M} \rightarrow\left[4 \mathrm{NI}^{\circ}\right]^{\#} \rightarrow(4 \mathrm{NI}-\mathrm{H})^{-}+\mathrm{H}^{\cdot}$

with $\left[4 \mathrm{NI}^{-}\right]^{\#}$ the transient anion formed upon electron attachment and $(4 \mathrm{NI}-\mathrm{H})^{-}$the closed shell dehydrogenated anion (112 amu) (Fig. 2). This reaction is operative within a series of narrow low energy resonances (Fig. 2) at energies below $2 \mathrm{eV}$ and within a broader resonance of higher energy. From the methylated compounds, a corresponding signal is observed at $112 \mathrm{amu}$, corresponding to $\left(\mathrm{Me} 5 \mathrm{NI}-\mathrm{CH}_{3}\right)^{-}$and $\left(\mathrm{Me} 4 \mathrm{NI}-\mathrm{CH}_{3}\right)^{-}$. These ions only appear at energies above $2 \mathrm{eV}$ which implicates that (a) methylation blocks dissociation at the N1-site, at low energies, as expected, and (b) in 4NI, the loss of hydrogen exclusively involves the N1-site. The small and narrow peak present in the ion yields from the methylated compounds right at threshold $(0 \mathrm{eV})$ is most likely an artefact and reminiscent to the peculiarities of DEA. ${ }^{22}$ 

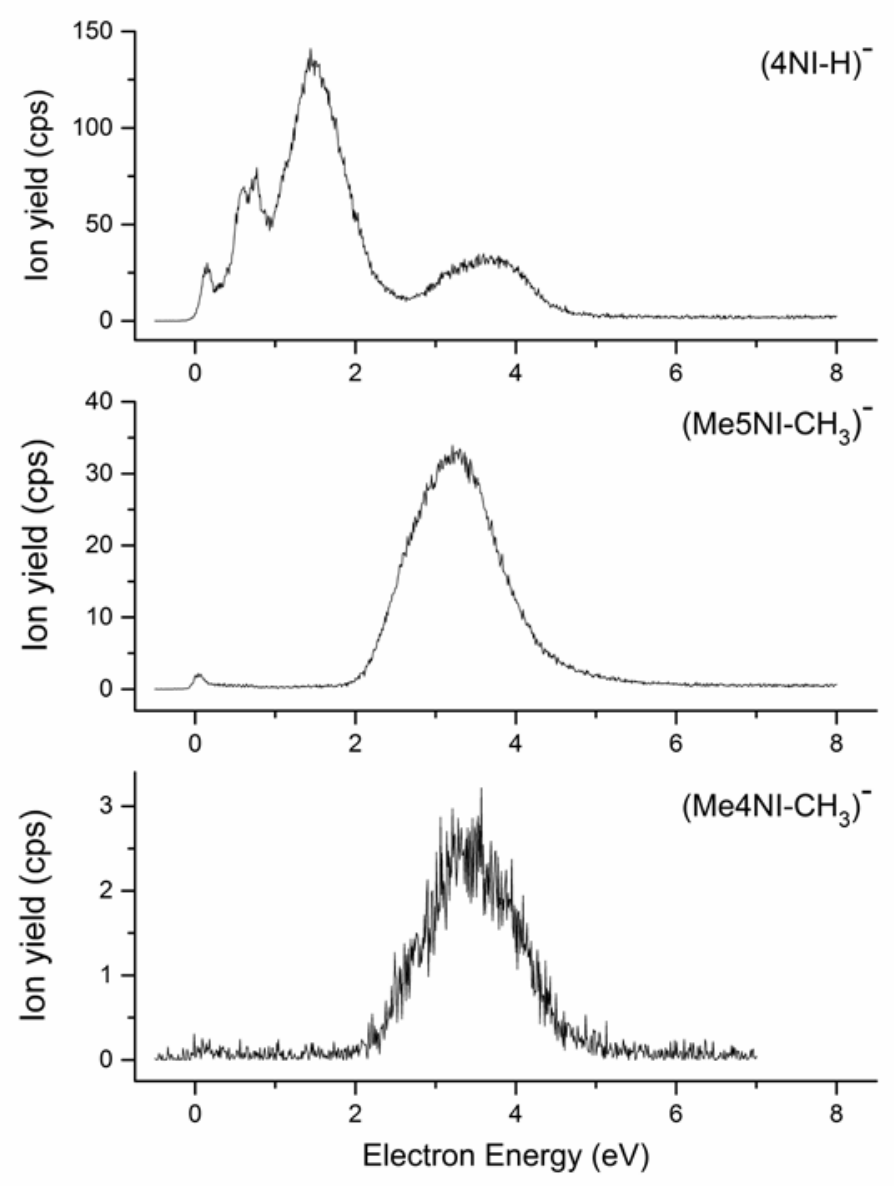

Fig. 2: Relative cross sections (ion yields) for the formation of (4NI-H) ${ }^{-}$(hydrogen loss, top) and $\left(\mathrm{Me} 5 \mathrm{NI}-\mathrm{CH}_{3}\right)^{-}$and $\left(\mathrm{Me} 4 \mathrm{NI}-\mathrm{CH}_{3}\right)^{-}$(loss of the methyl group). All three ions appear at 112 amu.

As already mentioned above, the low energy DEA resonances are interpreted as vibrational Feshbach resonances involving dipole supported states. For the broad and unstructured resonance at higher energy it is not obvious whether this transient anion can be characterised as a one particle shape resonance (attachment into a higher lying $\mathrm{MO}$ ) or as a core excited resonance, the latter associated with electronic excitation and hence two electrons in normally empty MOs. The 
fact that the higher energy resonance decomposes into a variety of fragments associated with very different unimolecular reactions strongly indicates that the involved electronic state does not possess a particular valence character but rather involves the entire molecule. However, it cannot be ruled out that different electronic states localised in the energy between 3 and $5 \mathrm{eV}$ contribute to the overall picture.

In the following we shall consider in more detail the different DEA reactions observed in the presented nitroimidazoles.

Cleavage of the $\mathrm{C}-\mathrm{NO}_{2}$ bond in the target molecules associated with the complementary ions $\mathrm{NO}_{2}^{-}$and $\left(\mathrm{M}-\mathrm{NO}_{2}\right)^{-}$

Together with hydrogen loss (reaction (3), only observed in 4NI), the two ions $\mathrm{NO}_{2}{ }^{-}$and $\left(\mathrm{M}-\mathrm{NO}_{2}\right)^{-}(\mathrm{M}=4 \mathrm{NI}, \mathrm{Me} 4 \mathrm{NI}, \mathrm{Me} 5 \mathrm{NI})$ are the result of the cleavage of one single bond $\left(\mathrm{C}-\mathrm{NO}_{2}\right)$ via DEA, all further reactions discussed below are considerably more complex mostly involving the entire molecule. Figure 3 shows the spectra for the formation of $\mathrm{NO}_{2}{ }^{-}$and in Figure 4 the spectra of $\left(\mathrm{M}-\mathrm{NO}_{2}\right)^{-}$, i.e., the loss of a neutral $\mathrm{NO}_{2}{ }^{\cdot}$ unit. Both fragment ions are complementary in the sense that they arise from the cleavage of the $\mathrm{C}-\mathrm{NO}_{2}$ bond with the excess charge finally localised on either of the two fragments according to

$$
\begin{aligned}
& \mathrm{e}^{-}+\mathrm{M} \rightarrow\left(\mathrm{M}-\mathrm{NO}_{2}\right)^{\cdot}+\mathrm{NO}_{2}^{-} \\
& \mathrm{e}^{-}+\mathrm{M} \rightarrow\left(\mathrm{M}-\mathrm{NO}_{2}\right)^{-}+\mathrm{NO}_{2}{ }^{-}
\end{aligned}
$$


Apparently for both of these complementary ions $\mathrm{NO}_{2}{ }^{-}$and $\left(\mathrm{M}-\mathrm{NO}_{2}\right)^{-}$the reaction below $2 \mathrm{eV}$ is completely suppressed in Me4NI and Me5NI. The reaction enthalpy $\left(\Delta \mathrm{H}^{\circ}\right)$ for the DEA reactions (4a) and (4b) is given by the number of the $\mathrm{D}\left(\mathrm{C}-\mathrm{NO}_{2}\right)$ bond dissociation energy minus the electron affinity of the fragment on which the excess energy finally becomes localised. For (4a) the threshold energy can be obtained by from established data as $\Delta \mathrm{H}^{\circ}=0.8 \mathrm{eV}^{8}$ which approximately fits to the position of the lowest resonance present in the $\mathrm{NO}_{2}{ }^{-} / 4 \mathrm{NI}$ yield and taken into account that at elevated temperature of the target molecule the appearance energy of a fragment can be shifted to lower energies. ${ }^{4}$ Like above, the small and narrow peak present in the $\mathrm{NO}_{2}{ }^{-}$yield from the methylated compounds right at threshold $(0 \mathrm{eV})$ is considered as an artefact due to the peculiarities of DEA. ${ }^{22}$ No fragments below $2 \mathrm{eV}$ are hence observed in the methylated compounds which indicates that methylation not only blocks dissociation from the N1 site, but also dissociation at the C4 and C5 position in line with the statement from above that the methylation blocks the doorway to DEA at energies below $2 \mathrm{eV}$.

It should be mentioned that at sufficiently high electron energies one may have a dissociation into more than one neutral particle. This is particularly the case for ions arising within the small structure seen on the high energy tale of some of the ion yields in Figs. 3 and 4. In the case of $\mathrm{NO}_{2}{ }^{-} / 4 \mathrm{NI}$ the excess energy for reaction (4a) amounts to about $5 \mathrm{eV}$ which is sufficient to further decompose the neutral counterpart. 

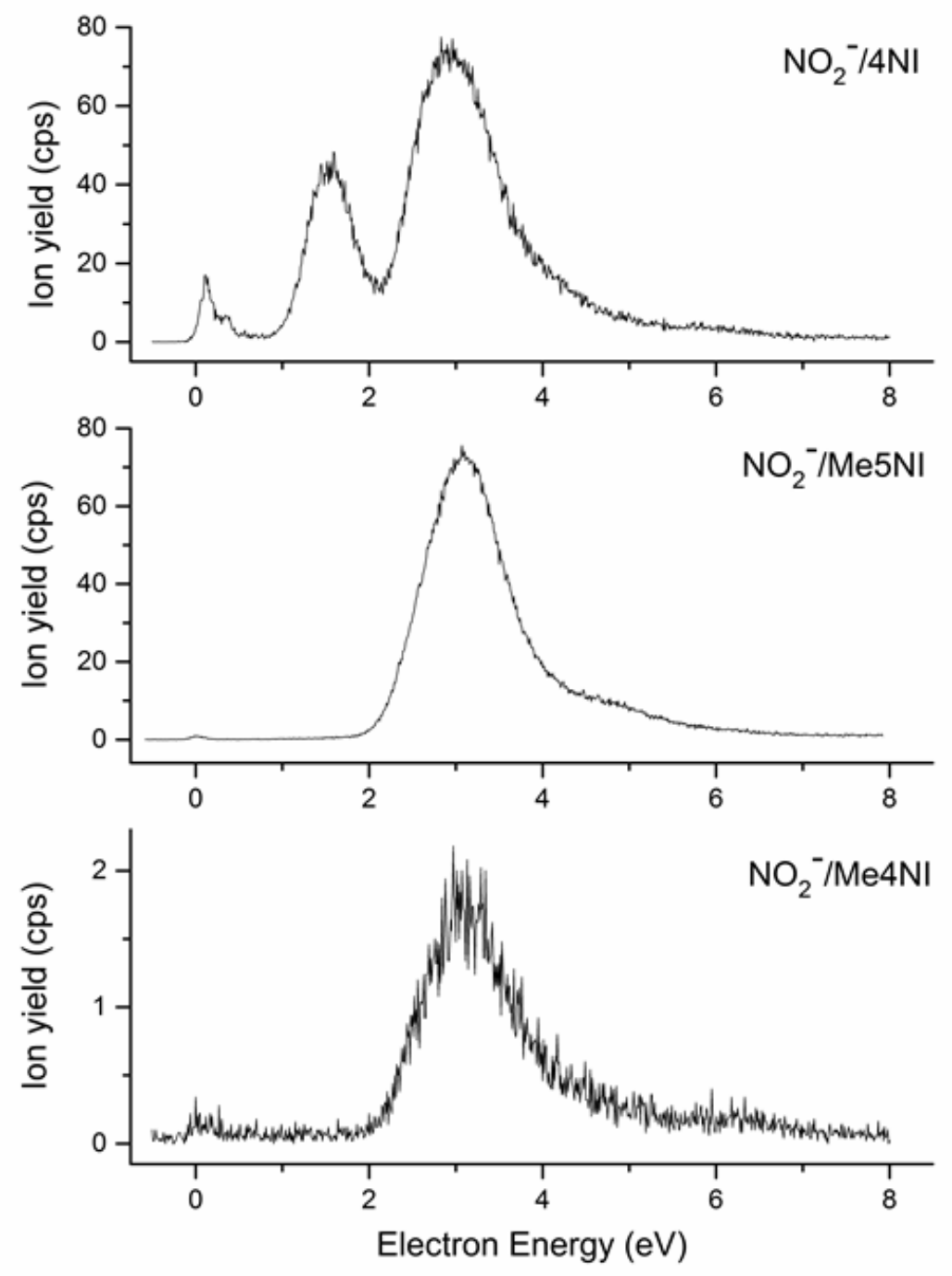

Fig. 3: Relative cross section for the formation of $\mathrm{NO}_{2}{ }^{-}$from 4NI (top), from Me5NI (middle) and from Me4NI (bottom). 

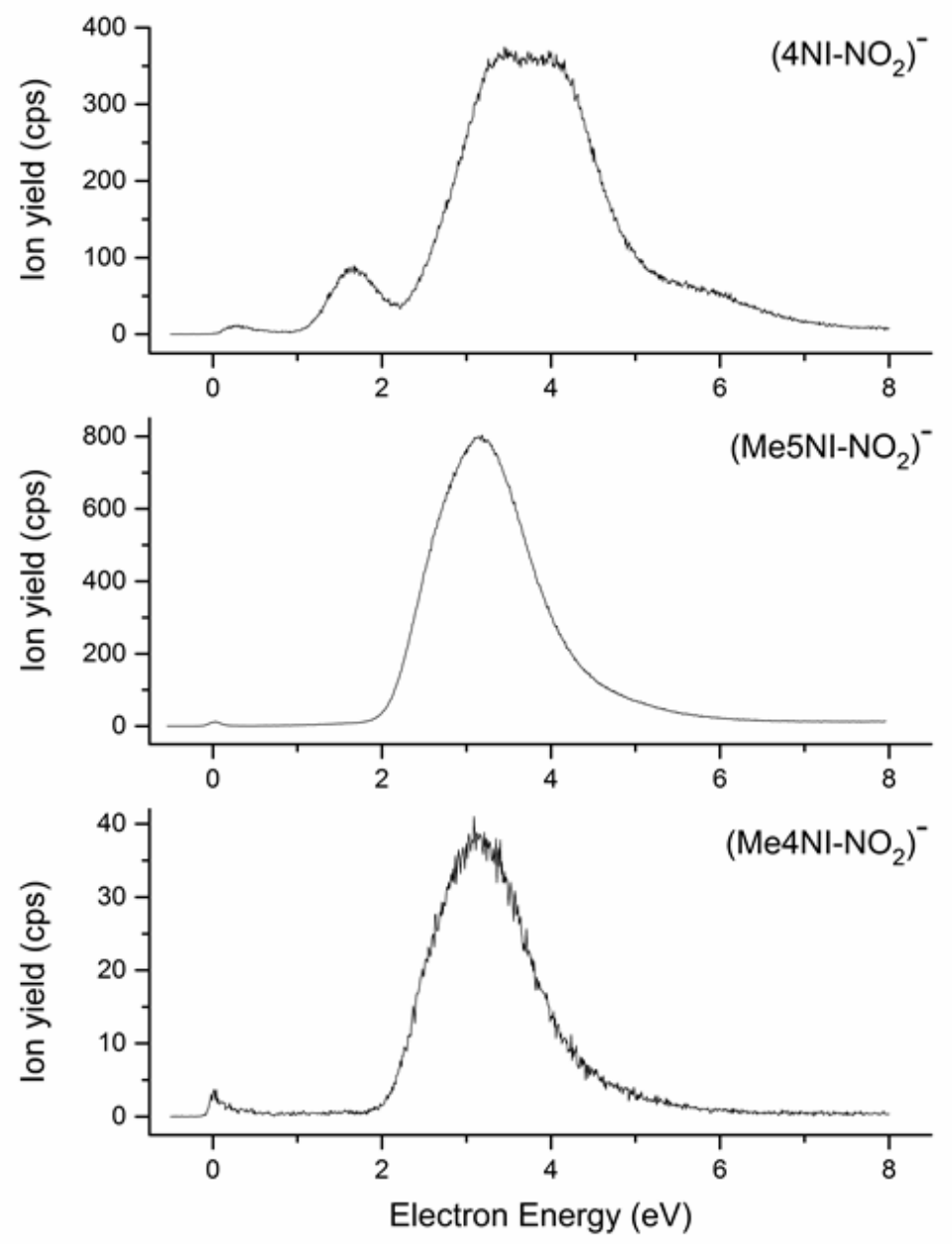

Fig. 4: Relative cross section for the ion appearing from the loss of a neutral $\mathrm{NO}_{2}$ unit, $\left(4 \mathrm{NI}-\mathrm{NO}_{2}\right)^{-}$(top), $\left(\mathrm{Me} 5 \mathrm{NI}-\mathrm{NO}_{2}\right)^{-}$(middle) and $\left(\mathrm{Me} 4 \mathrm{NI}-\mathrm{NO}_{2}\right)^{-}$(bottom).

\section{Loss of a Neutral ${ }^{\circ} \mathrm{OH}$ unit (Formation of $(\mathrm{M}-\mathrm{OH})^{-}$)}

The loss of a neutral ${ }^{\circ} \mathrm{OH}$ unit resulting in the ion $(\mathrm{M}-\mathrm{OH})^{-}$is detected at 96 amu from $4 \mathrm{NI}$ and at 110 amu from Me5NI and Me4NI (Fig. 5). Again, the reaction is quenched in the two methylated molecules in the energy domain below $2 \mathrm{eV}$ indicating that the Feshbach resonances present in 4NI couple to valence configurations associated with multiple bond cleavages. In all 
three compounds the reaction requires the cleavage of two bonds $(\mathrm{N}-\mathrm{O})$ and $\mathrm{C}-\mathrm{H}(\mathrm{or} \mathrm{N}-\mathrm{H})$ and formation of $\mathrm{O}-\mathrm{H}$.
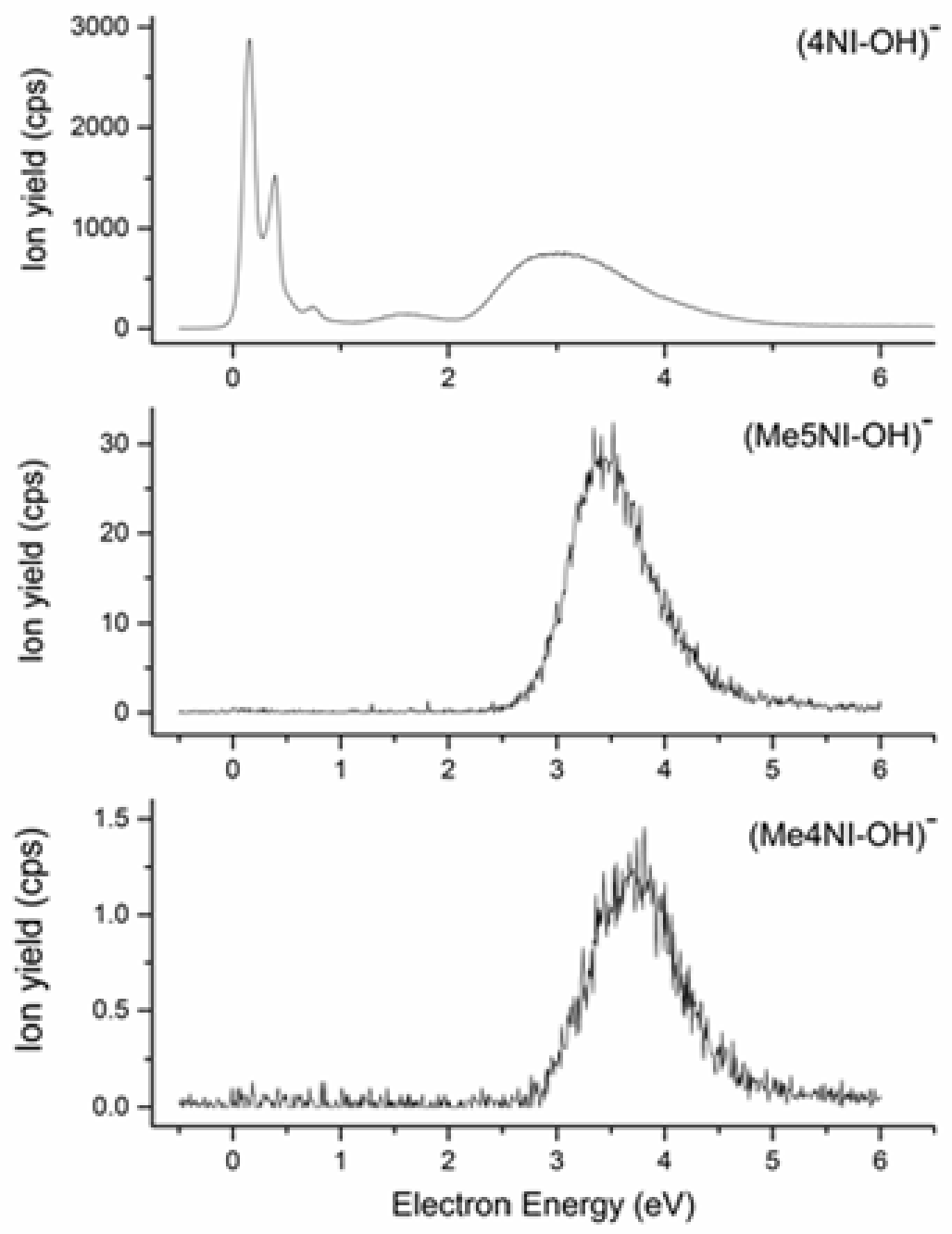

Fig. 5: Relative cross section for the ion appearing from the loss of a neutral $\mathrm{OH}$ unit, $(4 \mathrm{NI}-\mathrm{OH})^{-}$(top), $(\mathrm{Me} 5 \mathrm{NI}-\mathrm{OH})^{-}$(middle) and (Me4NI-OH) ${ }^{-}$(bottom). 
The fact that the intensity of this ion is significantly higher in 4NI compared to Me4NI and Me5NI (with the usual difference between Me4NI and Me5NI) is a strong indication that the $\mathrm{N} 1-\mathrm{H}$ bond is involved. For the neutral compound the loss of an ${ }^{\circ} \mathrm{OH}$ would require several eV which means that in the DEA reaction a corresponding relaxation energy including the binding energy for the excess charge must compensate the decrease of the binding order along the reaction.

\section{Formation of $\mathrm{CN}^{-}$}

This fragment is observed from all three title compounds with the usual behaviour that methylation blocks its appearance at energies below $2 \mathrm{eV}$. $\mathrm{CN}^{-}$can be formed by involving an $\mathrm{N}$ atom either from the $\mathrm{NO}_{2}$ group or from the ring or an excision of a $\mathrm{CN}$ unit from the ring. In any case, it is a complex reaction associated with significant rearrangement in the transitory anion. The excision of $\mathrm{CN}^{-}$has previously been observed from organic molecules such as acetamide ${ }^{23}$ or DNA bases, ${ }^{24}$ in the latter case at higher energies and associated with the deterioration of the cyclic structure.

In 4NI formation of $\mathrm{CN}^{-}$formation is operative already near threshold and a possible scenario is that along a concerted reaction the molecule will completely degrade. In 4NI a complete degradation is possible through the reaction

$\mathrm{e}^{-}+\mathrm{C}_{3} \mathrm{H}_{3} \mathrm{~N}_{3} \mathrm{O}_{2} \rightarrow\left[\mathrm{C}_{3} \mathrm{H}_{3} \mathrm{~N}_{3} \mathrm{O}_{2}{ }^{-}\right]^{\#} \rightarrow \mathrm{CN}^{-}+\mathrm{CO}_{2}+\mathrm{N}_{2}+{ }^{\circ} \mathrm{CH}_{3}$

and, accordingly, for the methylated molecules 
$\mathrm{e}^{-}+\mathrm{C}_{4} \mathrm{H}_{5} \mathrm{~N}_{3} \mathrm{O}_{2} \rightarrow\left[\mathrm{C}_{4} \mathrm{H}_{5} \mathrm{~N}_{3} \mathrm{O}_{2}{ }^{\cdot}\right]^{\#} \rightarrow \mathrm{CN}^{-}+\mathrm{CO}_{2}+\mathrm{N}_{2}+{ }^{\circ} \mathrm{C}_{2} \mathrm{H}_{5}$

The reaction enthalpy of (5) and (6) cannot directly be derived as the heat of formation for the target molecules is not directly available from the literature. However, it can readily be estimated by taking that for imidazole $\left(\Delta \mathrm{H}_{\mathrm{f}}{ }^{\circ}=135 \pm 5 \mathrm{kJmol}^{-1}\right)^{25}$ and using analogies when replacing $\mathrm{H}$ by $\mathrm{NO}_{2}$ and $\mathrm{H}$ by $\mathrm{CH}_{3}$ (in prototype molecules like methane or benzene (see Table 1)) one arrives at the estimated numbers $\Delta \mathrm{H}_{\mathrm{f}}{ }^{\circ}(4 \mathrm{NI})=120 \mathrm{kJmol}^{-1}$ and $\Delta \mathrm{H}_{\mathrm{f}}{ }^{\circ}(\mathrm{Me} 4 \mathrm{NI})=110 \mathrm{kJmol}^{-1}$ which should be sufficiently accurate for a semi-quantitative consideration of the situation.

Table 1: Heats of formation $\left(\Delta \mathrm{H}_{\mathrm{f}}{ }^{\circ}\right)$ for some compounds relevant in the present reactions, taken from ref. 25

\section{Compound}

Imidazole $\left(\mathrm{C}_{3} \mathrm{H}_{4} \mathrm{~N}_{2}\right)$

$\mathrm{CN}$

$\mathrm{CO}_{2}$

$\mathrm{CH}_{3}$

$\mathrm{CH}_{4}$

$\mathrm{CH}_{3} \mathrm{NO}_{2}$

$\mathrm{CH}_{3} \mathrm{CH}_{2}$

$\mathrm{CH}_{3} \mathrm{CH}_{3}$

$\mathrm{CH}_{3} \mathrm{CH}_{2} \mathrm{NO}_{2}$ (liq)

$\mathrm{C}_{6} \mathrm{H}_{6}$

$\mathrm{C}_{6} \mathrm{H}_{5} \mathrm{CH}_{3}$

\section{$\Delta \mathbf{H}_{\mathrm{f}}^{\circ}\left(\mathrm{kJmol}^{-1}\right)$}

\section{$135 \pm 5^{\mathrm{a}}$}

435.14

$-393.51 \pm 0.13$

145.7

$-74.87$

$-81 \pm 1$

$119 \pm 2$

$-84 \pm 0.4$

$-144$

$82.9 \pm 0.1$

$50.1 \pm 1.1$

\footnotetext{
${ }^{\mathrm{a}}$ mean value of different data ranging between 130 and $140 \mathrm{kJmol}^{-1}$
} 

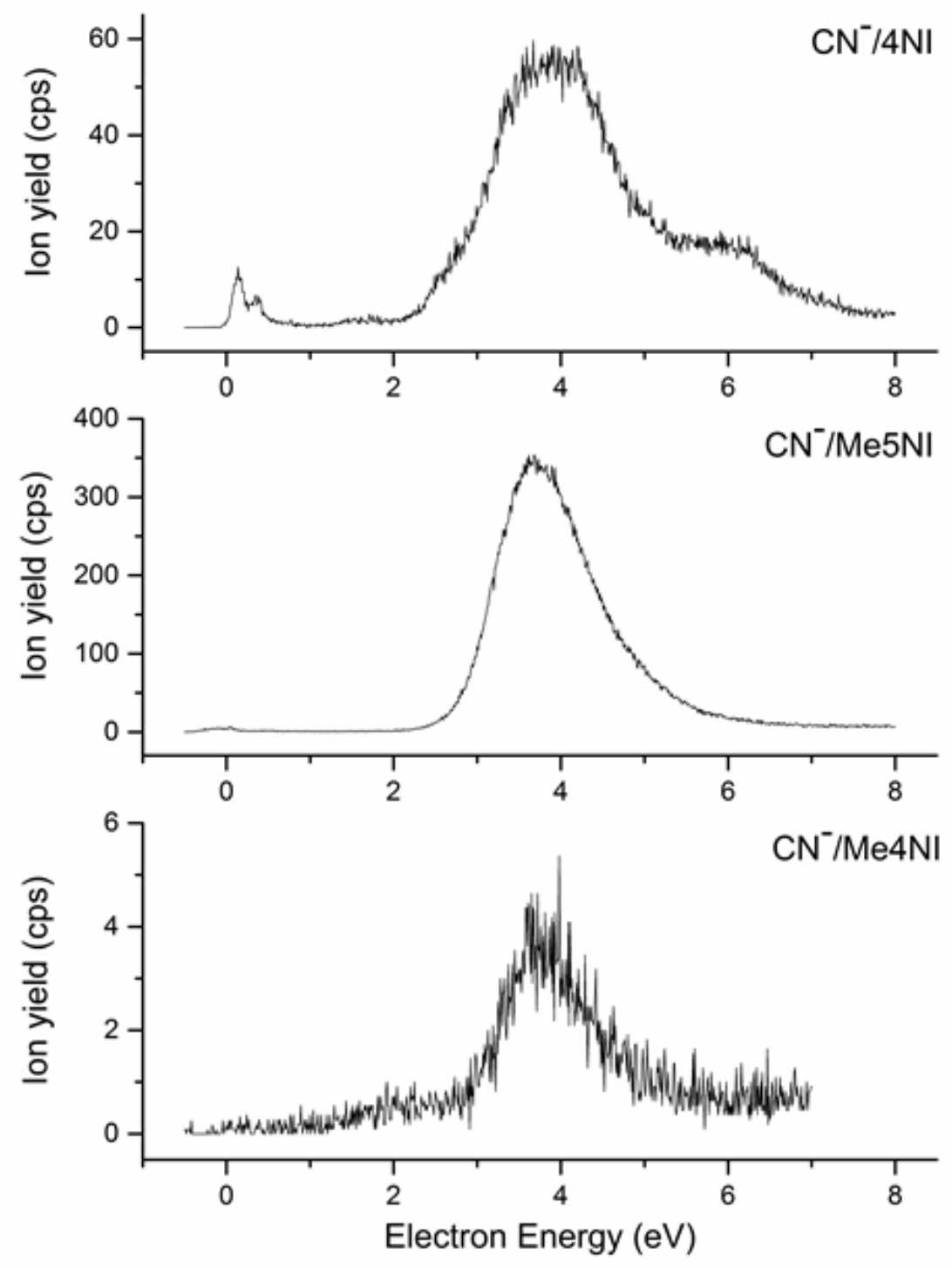

Fig. 6: Relative cross section for $\mathrm{CN}^{-}$formation from 4NI (top), from Me5NI (middle) and from Me4NI (bottom). 
Taking the numbers from Table 1, and the electron affinity of $\mathrm{CN}(3.86 \mathrm{eV})^{25}$ we arrive at the reaction enthalpies $\Delta \mathrm{H}_{\mathrm{R}}{ }^{\circ}(5)=-3.2 \mathrm{eV}$ and $\Delta \mathrm{H}_{\mathrm{R}}{ }^{\circ}(6)=-3.3 \mathrm{eV}$. Although it is not obvious that $\mathrm{CN}^{-}$formation in fact arises along a complete degradation, the example illustrates an interesting aspect on the stability of the target compounds. In the neutral system, the reaction enthalpy for the complete degradation is by the electron affinity of the $\mathrm{CN}$ molecule higher which makes the complete degradation reaction slightly endothermic. Thus, just the presence of an extra charge (with no extra energy) transforms the thermodynamically stable molecules into highly reactive systems and furthermore, the corresponding DEA doorways can be blocked by methylation.

The decomposition of 4NI and Me5NI (as model compounds of new imidazole based energetic materials) following UV excitation at (226, 236 and $248 \mathrm{~nm}$ ) has recently been explored by ns energy resolved spectroscopy. ${ }^{26}$ It was found, that in both molecules NO ${ }^{\circ}$ is formed as an initial product, irrespective of the excitation wavelength.

\section{Formation of $\left(\mathrm{M}-\mathrm{HNO}_{2}\right)^{\cdot-}$ and $\left(\mathrm{M}-\mathrm{CO}_{2}\right)^{\cdot-}$}

The spectra due to the loss of a neutral $\mathrm{HNO}_{2}$ unit are presented in Fig. 7, indicating that the formation is blocked by methylation in the low energy range.

In the first case a likely reaction pathway is the concerted cleavage of the $\mathrm{C}-\mathrm{NO}_{2}$ bond, and cleavage of either a $\mathrm{C}-\mathrm{H}$ or $\mathrm{N}-\mathrm{H}$ bond and rearrangement to $\mathrm{HNO}_{2}$. Since the mass spectrometer is detecting only ions, we do not have information on the neutral counterpart. At low energy (below $2 \mathrm{eV}$ ) it is likely that recombination to $\mathrm{HNO}_{2}$ is in fact required to energetically drive the reaction. At higher electron energies (within the broad resonance) it is 
possible that the neutral counterpart consists of more than one particle, e.g., $\mathrm{H}^{*}+\mathrm{NO}_{2}{ }^{\circ}$ without recombination.
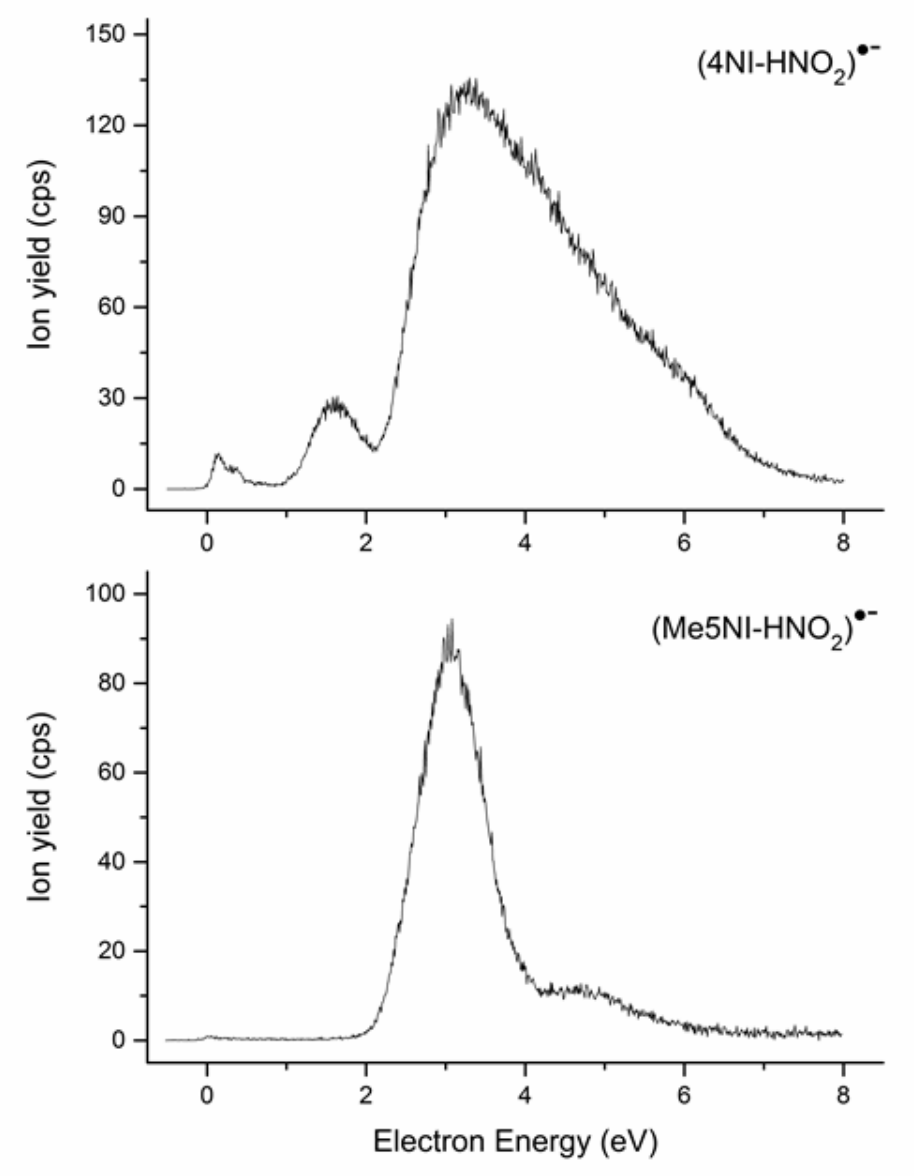

Fig. 7: Relative cross section for the ion appearing from the loss of a neutral $\mathrm{HNO}_{2}$ unit, $\left(4 \mathrm{NI}-\mathrm{HNO}_{2}\right)^{-}$, (top) and (Me5NI-HNO $)^{-}$(bottom).

A further fragment ion is observed at $69 \mathrm{amu}$ (from 4NI) and 83amu (from Me5NI) which can be assigned to $\left(\mathrm{M}-\mathrm{CO}_{2}\right)^{\circ-}$. The loss of $\mathrm{CO}_{2}$ requires significant rearrangement in the transient negative ion accompanied by several bond cleavages. The ion yields show the usual behaviour 
that the reaction is quenched under the methylation below $2 \mathrm{eV}$ (not shown here). Owing to the high stability of $\mathrm{CO}_{2}$, the fragmentation of the neutral counterpart can be ruled out within the energy range under observation. It should be noted that the corresponding ion signals from Me4NI are below the detection limit. This is also true for the NO-loss reactions in Fig. 8 .

\section{Formation of $(\mathrm{M}-\mathrm{NO})^{-}$}

The loss of an $\mathrm{NO}^{\circ}$ unit from 4NI and Me5NI (Fig. 8), finally shows an unusual behaviour in the way that the reaction is strongly present in 4NI while it still remains weakly detectable in Me5NI. In addition, in 4NI the reaction is restricted to the low energy resonances with virtually no intensity in the energy range of the broad resonance at higher energy. In Me5NI the overall intensity is much lower but it is apparent that methylation does not completely block the reaction at low energies as was the case for all the other unimolecular reactions presented here.

Electronic excitation of $4 \mathrm{NI}$ and Me5NI by UV photons ${ }^{26}$ generates $\mathrm{NO}^{\circ}$ as an initial decomposition product with a rotationally cold (50 K) and vibrationally warm (800 K) distribution, independent of the excitation wavelength. Photoexcitation eventually creates more neutral products which are not easily accessed by spectroscopic methods. In the case of NO formation via DEA, however, the significant difference between 4NI and Me5NI is apparent from Fig. 8. 

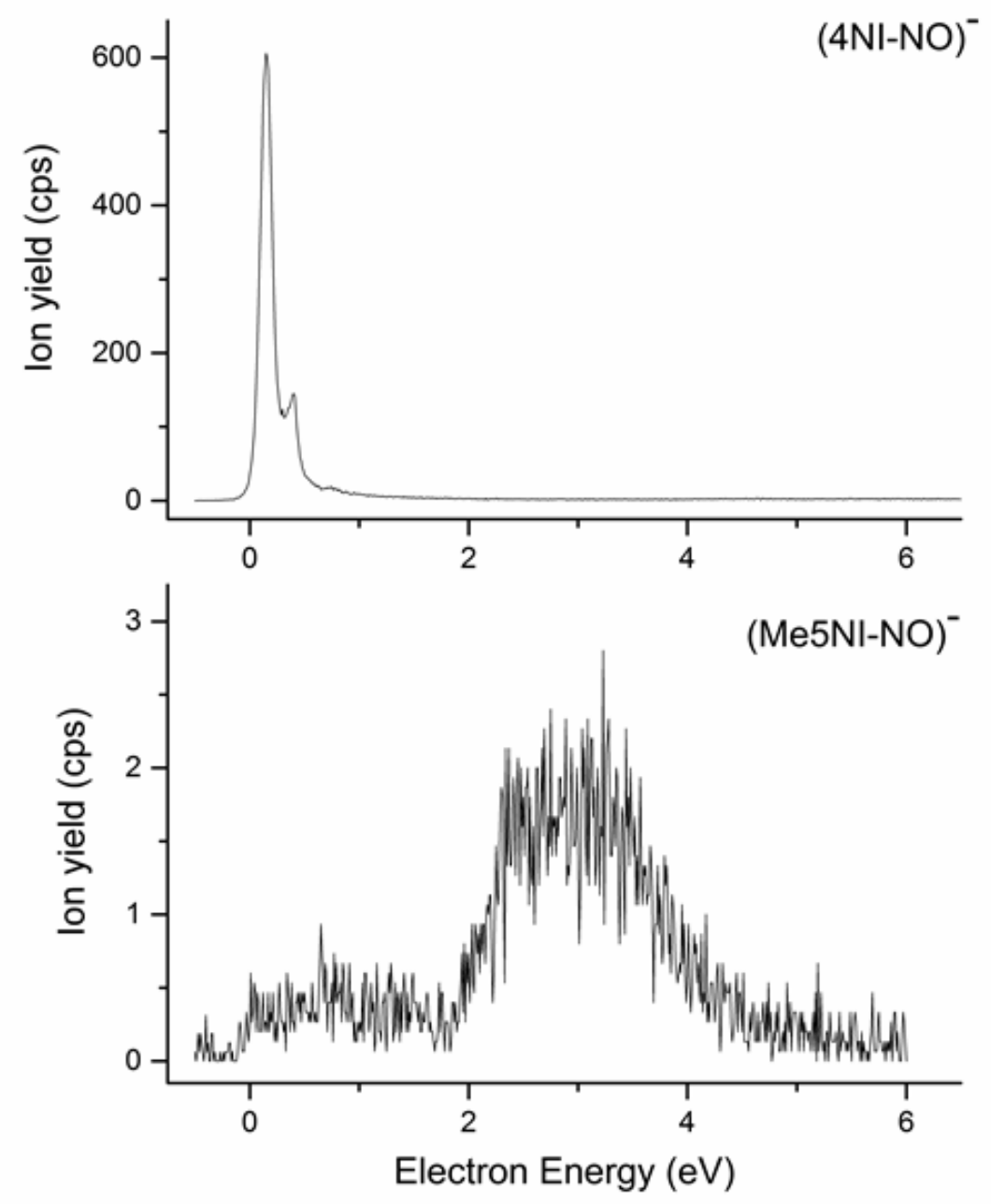

Fig. 8: Relative cross section for the ion appearing from the loss of a neutral NO unit, (4NI-NO) ${ }^{-}$(bottom), and (Me5NI-NO) ${ }^{-}$(bottom). 


\section{CONCLUSIONS}

The attachment of electrons to 4NI, Me4NI and Me5NI triggers a variety of unimolecular reactions via DEA including simple bond cleavages (formation of $\mathrm{NO}_{2}{ }^{-}$, loss of $\mathrm{H}^{\circ}$ ) and complex reactions involving the entire molecule thereby generating new entities (loss of ${ }^{\circ} \mathrm{OH}$, loss of $\mathrm{HNO}_{2}$, etc.). Methylation completely blocks the DEA reactions in the energy range below $2 \mathrm{eV}$. Only the methylated compounds do form metastable parent anions with a sharp resonance right at threshold $(0 \mathrm{eV})$, favoured by the fact that the competitive DEA processes are quenched at low energies. Concerning their action as radiosensitisers the property of 4NI to effectively generate radicals at very low energies (which in turn can attack tumour cells) is a possible key towards the understanding of the underlying molecular mechanisms. This ability of radical formation at low energies is completely quenched in the methylated analogues.

\section{AUTHOR INFORMATION}

\section{Corresponding Authors}

*1.feketeova@ipnl.in2p3.fr, Stephan.Denifl@uibk.ac.at

\section{ACKNOWLEDGMENT}

This work was partially supported by the Austrian Science Fund FWF (P22665). LF thanks the ARC for financial support via the ARC Centre of Excellence program and for the award of an APD. 


\section{ABBREVIATIONS}

4NI, 4-nitroimidazole; Me4NI, 1-methyl-4-nitroimidazole; Me5NI, 1-methyl-5-nitroimidazole;

LEE, low energy electrons; DEA, dissociative electron attachment; TNI, transient negative ion. 


\section{REFERENCES}

1. Overgaard, J.; Hansen, H.S.; Overgaard, M.; Bastholt, L.; Berthelsen, A.; Specht, L.; Lindeløv B.; Jørgensen, K. A Randomized Double-Blind Phase III Study of Nimorazole as a Hypoxic Radiosensitizer of Primary Radiotherapy in Supraglottic Larynx and Pharynx

Carcinoma. Results of the Danish Head and Neck Cancer Study (DAHANCA) Protocol 5-85. Radiother. Oncol. 1998, 46, 135-146.

2. Overgaard, J. Hypoxic Modification of Radiotherapy in Squamous Cell Carcinoma of the Head and Neck - A Systematic Review and Meta-Analysis. Radiother. Oncol. 2011, 100, 22-32.

3. Park, Y.; Polska, K.; Rak, J.; Wagner, J. R.; Sanche, L. Fundamental Mechanisms of DNA Radiosensitization: Damage Induced by Low-Energy Electrons in Brominated Oligonucleotide Trimers. J. Phys. Chem. B 2012, 116, 9676-9682.

4. Illenberger E.; Momigny, J. Gaseous Molecular Ions. An Introduction to Elementary Processes Induced by Ionization; Steinkopff Verlag, Darmstadt / Springer-Verlag, New York 1992.

5. Baccarelli, I.; Bald, I.; Gianturco, F.A.; Illenberger E.; Kopyra. Electron-Induced Damage of DNA and Its Components: Experiments and Theoretical Models. J. Phys. Rep. 2011, $508,1-44$.

6. Abdoul-Carime, H.; Huels, M.A.; Brüning, F.; Illenberger, E.; Sanche, L. Dissociative Electron Attachment to Gas-Phase 5-Bromouracil. J.Chem.Phys. 2000, 113, 2517-2521. 
7. Abdoul-Carime, H.; Huels, M.A.; Illenberger, E.; Sanche, L. Sensitizing DNA to Secondary Electron Damage: Resonant Formation of Oxidative Radicals from 5-Halouracils. J. Am. Chem. Soc. 2001, 123, 5354-5355.

8. Tanzer, K.; Feketeová, L.; Puschnigg, B.; Scherer, P.; Illenberger, E.; Denifl, S. Reactions in Nitroimidazole Triggered by Low-Energy (0-2 eV) Electrons: Methylation at N1-H Completely Blocks Reactivity. Angew. Chem. Int. Ed. 2014, 53, 12240-12243.

9. Hotop, H.; Ruf, M.-W.; Allan, M.; Fabrikant, I. Resonance and Threshold Phenomena in Low-Energy Electron Collisions with Molecules and Clusters. Adv. At. Mol. Opt. Phys. 2003, 49, 85-216.

10. Desfrancois, C. Determination of Electron-Binding Energies of Ground-State DipoleBound Molecular Anions. Phys. Rev. A 1995, 51, 3667-3675.

11. Sommerfeld, T. Coupling Between Dipole-Bound and Valence States: the Nitromethane Anion. Phys. Chem. Chem. Phys. 2002, 4, 2511-2516.

12. Feketeová, L;. Albright, A. L.; Sørensen, B. S.; Horsman, M. R.; White, J.; O’Hair, R. A. J.; Bassler, N. Formation of Radical Anions of Radiosensitizers and Related Model Compounds via Electrospray Ionization. Int. J. Mass Spectrom. 2014, 365-366, 56-63.

13. Denifl, S.; Ptasinska, S.; Sonnweber, B.; Scheier, P.; Liu, D.; Hagelberg, F.; Mack, J.; Scott, L.; Märk, T. D. Free-Electron Attachment to Coronene and Corannulene in the Gas Phase. J. Chem. Phys. 2005, 123, 104308. 
14. Illenberger, E. Electron Attachment Processes in Free and Bound Molecules, in Photoionization, Part II, pp. 1063-1160; Advanced Series in Physical Chemistry-Vol. 10B, edited by C.-Y. Ng, Wold Scientific, Singapore, 2000.

15. Christophorou L. G.; Olthoff, J. K. Fundamental Electron Interactions with Plasma Processing Gases; Kluwer Academic, New York, 2004.

16. Klar, D.; Ruf M.-W.; Hotop, H. Dissociative Electron Attachment to $\mathrm{CCl}_{4}$ Molecules at Low Electron Energies with meV Resolution. Int. J. Mass Spectrom. 2001, 205, 93-110.

17. Sulzer, P.; Rondino, F.; Ptasinska, S.; Illenberger, E.; Märk T. D.; Scheier, P. Probing Trinitrotoluene (TNT) by Low-Energy Electrons: Strong Fragmentation Following Attachment of Electrons Near 0 eV. Int. J. Mass Spectrom. 2008, 271, 149-153.

18. Sulzer, P.; Mauracher, A.; Denifl, S.; Probst, M.; Märk, T. D.; Scheier, P.; Illenberger, E. Probing Di-Nitrobenzene by Low Energy Electrons Identification of Isomers via Resonances in Dissociative Electron Attachment. Int. J. Mass Spectrom. 2007, 266, 138-148.

19. Jaffke, T.; Illenberger, E.; Lezius, M.; Matejcik, S.; Smith D.; Märk, T.D. Formation of $\mathrm{C}_{60}{ }^{-}$and $\mathrm{C}_{70}{ }^{-}$by Free-Electron Capture - Activation-Energy and Effect of the Internal Energy on Lifetime. Chem. Phys. Let. 1994, 226, 213-218.

20. Matejcik, S.; Märk, T. D.; Spanel, P.; Smith, D.; Jaffke T.; Illenberger, E. Formation and Decay of $\mathrm{C}_{60}{ }^{-}$Following Free-Electron Capture by $\mathrm{C}_{60}$. J. Chem. Phys. 1995, 102, 2516-2521.

21. Elhamidi, O.; Pommier, J.; Abouaf, R. Low-Energy Electron Attachment to Fullerenes $\mathrm{C}_{60}$ and $\mathrm{C}_{70}$ in the Gas Phase. J. Phys. B, At. Mol. Opt. Phys. 1997, 30, 4633-4642. 
22. $\quad$ Langer, J.; Balog, R.; Stano, M.; Abdoul-Carime, H.; Illenberger, E. Low Energy Electron Driven Reactions in Free and Bound Molecules: from Unimolecular Processes in the Gas Phase to Complex Reactions in a Condensed Environment. Int. J. Mass Spectrom. 2004, 233, 267-291.

23. König-Lehmann, C.; Kopyra, J.; Dabkowska, I.; Kosicek, J.; Illenberger. E. Excision of $\mathrm{CN}^{-}$and $\mathrm{OCN}^{-}$from Acetamide and Some Amide Derivatives Triggered by Low Energy Electrons. Phys. Chem. Chem. Phys. 2008, 10, 6954-6961.

24. Denifl, S.; Ptasinska, S.; Probst, M.; Hrusak, J.; Scheier P.; Märk , T. D. Electron Attachment to the Gas-Phase DNA Bases Cytosine and Thymine. J. Phys. Chem. A 2004, 108, 6562-6569.

25. NIST Chemistry webbok: http://webbook.nist.gov/chemistry.

26. Yu Z.; Bernstein, E.R. Experimental and Theoretical Studies of the Decomposition of New Imidazole Based Energetic Materials: Model Systems. J. Chem. Phys. 2012, 137, 114303. 
TABLE OF CONTENTS GRAPHIC

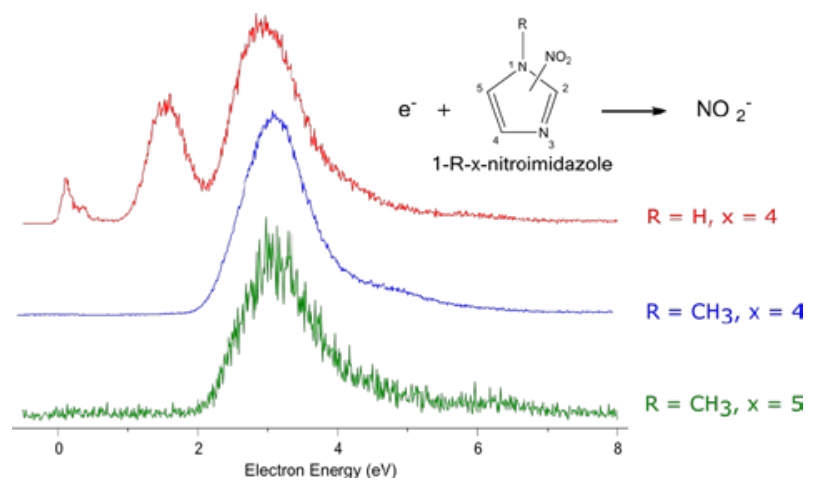

